\title{
Antimitochondrial Antibodies: from Bench to Bedside
}

\author{
Francesca Colapietro $^{1,2} \cdot$ Ana Lleo $^{1,2}$ - Elena Generali ${ }^{1,2}$ \\ Accepted: 13 September 2021 / Published online: 29 September 2021 \\ (c) The Author(s), under exclusive licence to Springer Science+Business Media, LLC, part of Springer Nature 2021
}

\begin{abstract}
Anti-mitochondrial antibodies (AMA) are directed against the E2 subunits of the 2-oxo acid dehydrogenase complexes (PDCE2) and are the typical biomarkers of primary biliary cholangitis (PBC), being present in 90-95\% of patients, with increasing sensitivity at increasing titers. Albeit being highly specific for PBC diagnosis, AMA can be detected in less than $1 \%$ of healthy subjects, and thus the management subjects with no sign or symptom of liver disease is still a challenge and data concerning clinical risk of developing PBC in this subgroup of patients are controversial. Moreover, AMA can also be detected in patients affected by overlap syndrome, as well as hepatic diseases (i.e., NASH and viral hepatitis), while the association with autoimmune diseases, in particular Sjögren's syndrome, systemic sclerosis, and systemic lupus erythematosus, is well established. Furthermore, new associations are being identified with inflammatory myositis and heart disease. AMA are directed towards the pyruvate dehydrogenase multi enzyme complex (PDC-E2) subunit, which represents an epithelial specific autoantigen for PBC. This review focuses on the main characteristics of AMA, their association with autoimmune diseases and liver diseases.
\end{abstract}

Keywords Autoimmunity $\cdot$ Primary biliary cholangitis $\cdot$ Systemic sclerosis $\cdot$ Myositis

\section{Introduction}

Autoantibodies represent the hallmark of autoimmune diseases (AID), playing a key role in the first steps of diagnostic approach to AID. Interestingly, autoantibodies may be present years before clinical manifestations develop [1].

Anti-mitochondrial antibodies (AMA) target lipoic acid containing immunodominant epitopes, particularly the E2 subunits of the 2-oxo acid dehydrogenase complexes (PDC-E2). However, AMA may target several antigens within the inner mitochondrial membrane, with no fully clear diagnostic and clinical significance known so far. PDC-E2 and E2 subunits of other mitochondrial autoantigens contain an essential lysine residue within the

Ana Lleo

ana.1leo@humanitas.it

1 Department of Biomedical Sciences, Humanitas University, Pieve Emanuele, Milan, Italy

2 Division of Internal Medicine and Hepatology, Department of Gastroenterology, Humanitas Research Hospital IRCCS, Rozzano, Milan, Italy lipoyl domain to which lipoic acid is covalently attached. This lipoic-lysine bond at position 173 is highly conserved across species and is necessary for antigen recognition [2].

At first, AMA were detected for a non-organ specific ATP-ase associated antigen called M2, consisting in several mitochondrial enzymatic polypeptides of which the dihydrolipoamide acetyltransferase ( $E_{2}$ component) of the pyruvate dehydrogenase multi enzyme complex (PDC-E2) is the most identified by AMA (M2-AMA) [3].

Afterwards, other subunit-specific AMA were identified all against components of the 2-oxoacid dehydrogenase (2-OADC) family of enzymes within the mitochondrial respiratory chain: the subunits-specific AMA type PDCE2, BCOADC-E2 (E2 subunit of the branched-chain 2-oxo acid dehydrogenase complex) and OGDC-E2 (E2 subunit of the 2-oxo-glutarate dehydrogenase complex). Besides E2 subunit, E1 and E3 are all subunits of these complexes participating in oxidative phosphorylation and have a great deal of homology, all of them containing the motif DKA, with lipoic acid covalently bound to the lysine $(\mathrm{K})$ residue [4]. Interestingly, PDC includes a fourth component, protein $\mathrm{X}$ (PDC-E3 binding protein, PDC-E3BP), which copurifies with E2. 


\section{Detection Methods}

The detection of AMA is currently recommended by the use of indirect immunofluorescence (IIF) on HEp-2 cells (Fig. 1) [5]. However, several multiplex assays, using methodological platforms such as enzyme-linked immunosorbent assay (ELISA), are becoming more common in diagnostic laboratories. An ELISA test directed towards M2-AMA showed a lower specificity than IIF, although being slightly more sensitive in biopsy-proven PBC [6]. Moreover, newer ELISA kits recognizing not only the M2 subunit, but also including the $3 \mathrm{E} 2$-subunits as a target, showed better performances [7]. Recently, dot blot has been proposed as a new testing for AMA with good performances [8]. These tests, however, need to be validated in large cohorts, and are therefore not recommended, and the gold standard for AMA detection remains IIF.

Thanks to the improvement of diagnostic methods, nine mitochondrial antigen/antibody patterns - from M1 to
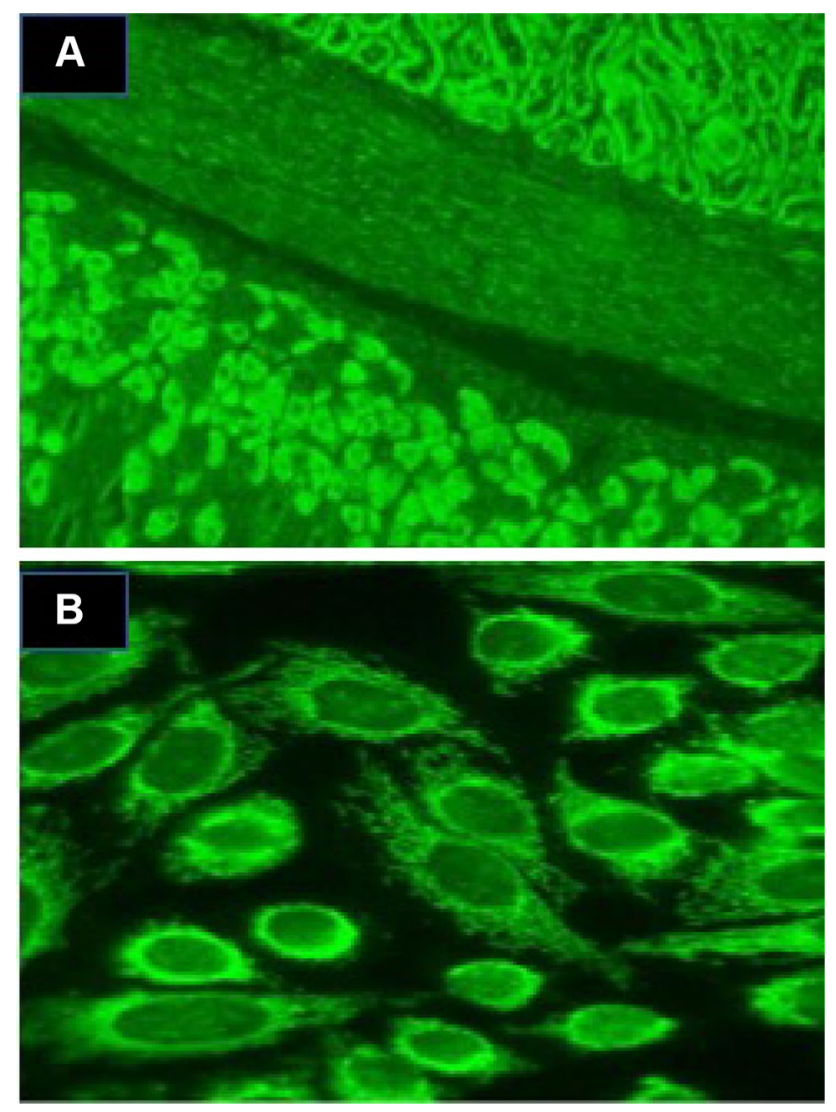

Fig. 1 Anti-mitochondrial antibodies detection by indirect immunofluorescence using HEp-2 cell or mouse tissue sections. A AMA staining of mouse kidney/smooth muscle/stomach tissue section showing staining of both proximal and distal tubules of the mouse kidney (upper right) and the parietal cells of the mouse stomach (lower left). B AMA on HEp-2 cells
M9 - have been described [9] being described not only in hepatic disorders but also in non-hepatic diseases. Interestingly, only M2, M4, M8, and M9 are specific for PBC [10]; however, anti-M4 and anti-M8 positivity probably represents artifacts of the methods used to detect AMA since they are both targets of AMA-M2 and are predictors of an elevated immunological activity of the disease. On the other hand, anti-M9, firstly described in 1984 by Klein and Berg, represents a markers of PBC even in anti-M2 PBC sera [11].

Anti-M1 ad anti-M7 have been detected in infectious disorders such as syphilis or myocarditis, while anti-M3 and M6 are associated with drug allergic reactions; anti-M5 have been detected in several collagen disorders [9]. Both M1 and M5 will be discussed later as they are associated with antiphospholipid syndrome.

\section{Clinical Associations}

\section{Anti-mitochondrial Antibodies in Liver Diseases}

\section{Primary Biliary Cholangitis}

PBC, previously known as primary biliary cirrhosis [12], is a chronic and cholestatic liver disease affecting mostly middle-aged women [13]. It is characterized by progressive, non-suppurative cholangitis involving biliary ducts, which are consequently destructed; the severe inflammation eventually leads to fibrosis and thus to liver cirrhosis with its complications [14]. Once the immune response is established, aberrant autoantigens are expressed on biliary epithelial cells, which may lead to an increased presentation to autoreactive $\mathrm{T}$ cells. After autoantigens have been presented, a multi-lineage $\mathrm{T}$ and subsequently $\mathrm{B}$ cell response develops. When symptomatic, up to $70 \%$ of patients present with fatigue or pruritus (usually at night). Rarely the onset of the disease is represented by the complications of cirrhosis such as ascites, jaundice, hepatic encephalopathy, upper gastrointestinal bleeding, or hepatocellular carcinoma [15].

The diagnosis of $\mathrm{PBC}$ relies on three main elements: 1) biochemical liver cholestasis with elevation of alkaline phosphatase (ALP) 2) detection of anti-mitochondrial antibody, 2-oxo-glutaric acid dehydrogenase complex (PDC-E2), and PBC-specific anti-nuclear antibodies ANA (anti-GP210, and/or anti-SP100) 3) suggestive histology obtained through liver biopsy [16]. Of note, AMA detection is often associated with a non-specific elevation of serum IgM concentration $[10,17]$.

The etiology of PBC is still obscure, but many data suggest that a genetic predisposing background together with infective, immunological and environmental risk factors may explain the onset of the disease [18]. Several studies have reported a strong link with HLA alleles, in particular 
DRB1*08, DR3, DPB1*0301, DRB 1*08-DQA1*0401DQB $1 * 04$, whereas DRB $1 * 11$ and DRB $1 * 13$ seem to be protective. Furthermore, non-HLA genes have been associated with $\mathrm{PBC}$ development, i.e., genes involved in the regulation of the immune system and antigen presentation, such as IL-1RL1, STAT4, STAT1, and IL12A [19]. Concerning environmental factors, infections are thought to increase the susceptibility to PBC based on molecular mimicry which ensues when an infectious agent, bacterial or viral, presents antigens with a significant amino acid similarity to self-proteins [20]. Furthermore, smoking, the use of hormonal replacement therapy and history of recurrent urinary tract infections have been associated with an increased risk of PBC development. Moreover, xenobiotics, such as nail varnish, hair dye, and cleaning chemicals can break selftolerance [21].

For unknown reasons PDC-E2 is aberrantly expressed in the luminal surface of bile duct epithelial cells of PBC patients, in a pathogenetic process that has been entitled "autoimmune epithelitis", shared with Sjögren's syndrome (Fig. 2) [20]. CD8 + T cells do recognize this epitope and are responsible for subsequent bile duct damage together with accumulation of bile acids, which reach toxic concentrations due to cholestasis $[22,23]$. In addition to the T-lymphocyte mediated destruction of small bile ducts, secondary damage to hepatocytes may occur from the accumulation in the liver of increased concentrations of potentially toxic substances, such as bile acids, which are normally secreted into the bile. The naturally occurring bile acids (cholic acid, chenodeoxycholic acid, and deoxycholic acid) are all detergents and can dissolve cell membranes if present in a sufficiently high concentration; such toxic concentrations are often reached in cholestasis [23].

AMA-M2 represent the hallmark of $\mathrm{PBC}$, being present in $90-95 \%$ of patients [24], and less than $1 \%$ of healthy subjects. Similar to other AID, AMA positivity might arise years before the development of PBC. Interestingly, IFAMA titers display a predictive value for $\mathrm{PBC}$ diagnosis, as titers of 1:320 and 1:640 increase the OR of 4.93 and 7.67, respectively. Studies demonstrate M2-AMA dot-blot to be more specific than IIF-AMA and suggest considering the determination of the number of M2-AMA specificities for PBC diagnosis [8]. Poyatos et al. recently observed that the combination of subunits-specific AMA positive increases both specificity and sensibility for PBC diagnosis (two M2-AMA specificities OR 2.05, $p$ 0.03; three M2-AMA

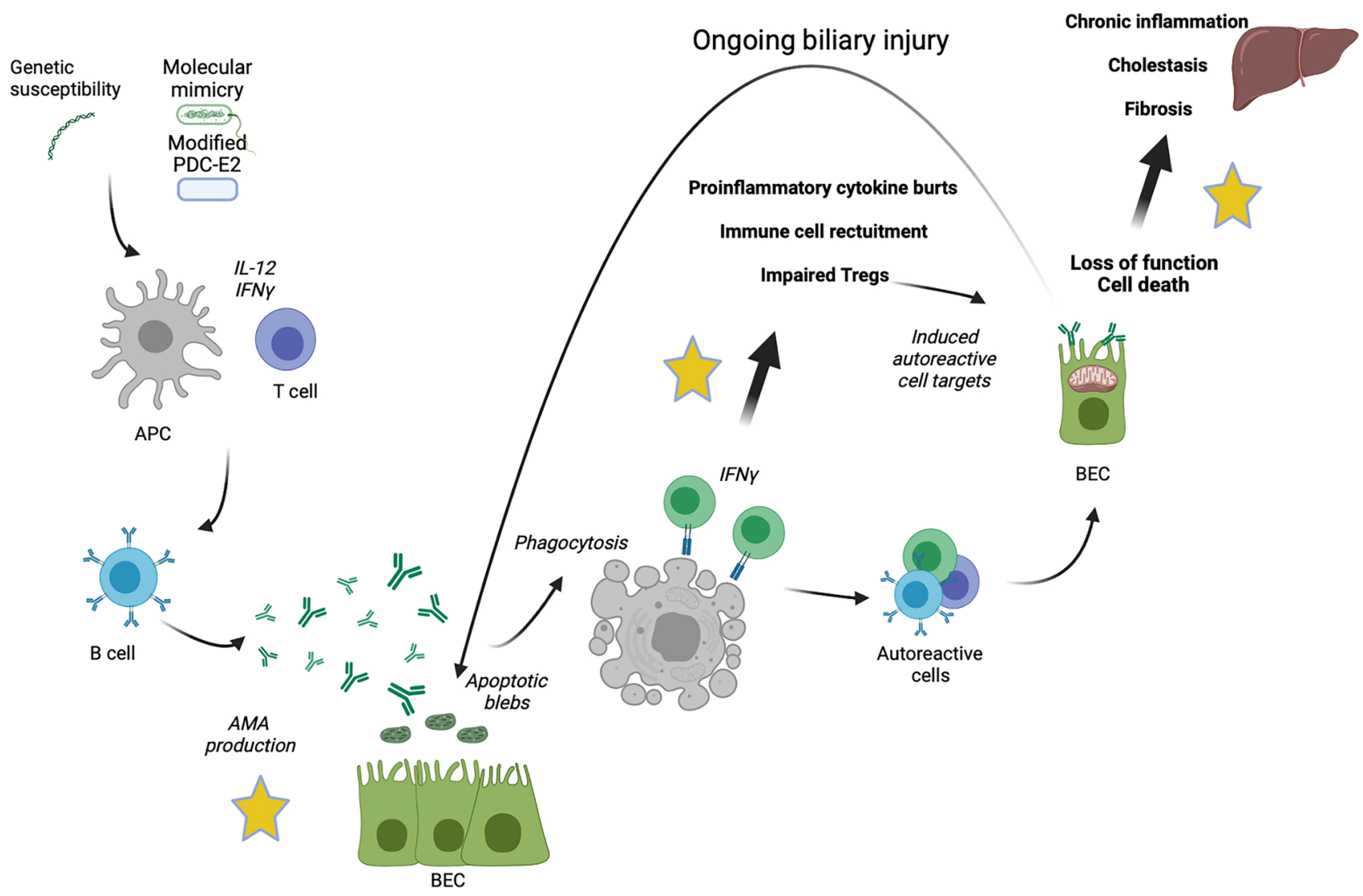

Fig. 2 Proposed pathogenetic mechanisms of primary biliary cholangitis APC, antigen presenting cell; PDC-E2, pyruvate dehydrogenase complex; IL, interleukin; IFN, interferon; AMA, anti-mitochondrial antibodies; BEC, biliary epithelial cells 
specificities OR 4.63, $p<0.0001$; four M2-AMA specificities OR 31.53, $p$ 0.006) [8].

Nevertheless, AMA testing is not specific for PBC, with AMA positivity up to $1 / 1000$ in general population compared to PBC prevalence up to $0.4 / 1000$ (Table 1) [13] Thus, management of subject tested positive for AMA with no sign or symptom of liver disease is still a challenge and data concerning clinical risk of developing PBC in this subgroup of patients are controversial. An old report by Metcalf et al. showed that up to $75 \%$ of AMA positive patients develop PBC after 18 years, with abnormal cholestatic liver tests at median time of 2 and 5 years, respectively, from the first AMA detection [25]. Other studies report lower rates of PBC diagnosis in AMA positive subjects, but with a mean follow-up of 5.8 years $[26,27]$. Both the study designs and the clinical course of the disease, which is slow and progressive, may explain the contrasting results. However, development of overt PBC in AMA positive subject is associated with risk factors such as high titer AMA, increased avidity of PDC-E2, and detection of autoantibodies targeting multiple cell domains [28]. Aside from its high specificity for PBC, AMA-M2 can be detected in a low percentage of autoimmune hepatitis type $1(\mathrm{AIH})$ and $\mathrm{SSc}$ patients
[29]. Although these are often cases of overlapping PBC, the measurement of AMA is certainly relevant for patients suspected of having PBC and may be critical in the prediction of PBC development for patients suffering from other autoimmune manifestations.

Despite their diagnostic value, AMAs have no prognostic value, nor their titer or their subtypes are associated with disease severity and outcome $[27,30,31]$. Since the titer usually remains stable over the years, serial testing during PBC follow-up is not recommended so far and does not have any predictive significance. Thus, even if treatment with ursodeoxycholic acid (UDCA) may decrease AMA titer, there is conflicting evidence that this effect is associated with treatment response [28, 32, 33]. Previous studies also reported that AMA could be detected in nearly all sera of patients transplanted for $\mathrm{PBC}$, without being associated with histological recurrence of PBC [34].

Interestingly, almost 5-10\% of PBC patients do not display detectable AMA using routinely methods, and are referred to as "AMA-negative"; remarkably, some cases of AMA negativity by IF result positive by western blot or ELISA [35, 36]. On the other hand, some studies have showed higher rates of ANA and ASMA positivity in the

Table 1 Anti-mitochondrial antibodies prevalence in autoimmune diseases, other diseases and healthy population

\begin{tabular}{|c|c|c|c|c|c|c|}
\hline Study & Year & Country & Population of study & Total subjects & Prevalence & Reference \\
\hline Assassi & 2009 & USA & Systemic sclerosis & 817 & $7 \%$ & {$[60]$} \\
\hline Cavazzana & 2011 & Italy & Systemic sclerosis & 201 & $21.4 \%$ & {$[65]$} \\
\hline Ceribelli & 2018 & Italy & Systemic sclerosis & 85 & $15 \%$ & [29] \\
\hline Generali & 2019 & Italy & Healthy population & 2685 & $3.8 \%$, high-titer $1 \%$ & Unpublished data \\
\hline Hatzis & 2008 & Greece & Sjogren's syndrome & 410 & $5.1 \%$ & [101] \\
\hline Imura-Kumada & 2012 & Japan & Systemic sclerosis & 225 & $16.4 \%$ & [102] \\
\hline Ranua & 2005 & Finland & $\begin{array}{l}\text { Epileptic patients vs. population-based } \\
\text { controls }\end{array}$ & $948+579$ & $3.9 \%$ vs. $1.9 \%$ & {$[103]$} \\
\hline Laadhar & 2007 & Tunisia & Type 1 diabetes & 161 & 0 & [104] \\
\hline Lazaridis & 2007 & USA & First degree $\mathrm{PBC}$ relatives & 306 & $13.1 \%$ & {$[105]$} \\
\hline $\mathbf{L i}$ & 2015 & China & Chronic hepatitis B & 325 & $6.8 \%$ & [106] \\
\hline $\mathbf{L i}$ & 2006 & China & Systemic lupus erythematosus & 365 & $15.3 \%$ & [71] \\
\hline Liu & 2018 & Meta-analysis & Vitiligo & 1 & $0.2 \%$ & [107] \\
\hline Maeda & 2012 & Japan & Inflammatory myopathies & 212 & $11.3 \%$ & [96] \\
\hline Marconcini & 2013 & Brazil & Chronic hepatitis $\mathrm{C}$ & 66 & $7.6 \%$ & [108] \\
\hline Mattalia & 1998 & Italy & Healthy population & 1530 & $0.5 \%$ & [109] \\
\hline Pelka & 2021 & Poland & Sub-acute cutaneous lupus erythematosus & 30 & $20 \%$ & [110] \\
\hline Pope & 1999 & Canada & Systemic sclerosis & 61 & $6.6 \%$ & [111] \\
\hline Ramos-Casals & 2005 & Spain & Chronic hepatitis C & 237 & $8 \%$ & [112] \\
\hline Shibata & 2004 & Japan & Corporate workers & 1714 & $0.64 \%$ & [113] \\
\hline Beretta-Piccoli & 2018 & Switzerland & Acute hepatitis E & 48 & $2.1 \%$ & [114] \\
\hline Turchany & 1997 & Estonia & Healthy population & 1461 & $0.89 \%$ & [115] \\
\hline Wielosz & 2016 & Poland & Systemic sclerosis & 86 & $13 \%$ & [116] \\
\hline Yokokawa & 2021 & Japan & Dilated cardiomyopathy & 270 & $1.1 \%$ & [117] \\
\hline Zografos & 2012 & Greece & First degree $\mathrm{PBC}$ relatives & 101 & $18.8 \%$ & [118] \\
\hline
\end{tabular}


AMA negative group as well as lower IgM levels $[37,38]$. Current literature has not evidenced any difference between the two groups concerning histology, clinical features, biochemistry, and response to UDCA [39]. Conversely, AMA negative subjects may have a more progressive disease due to delayed diagnosis and UDCA treatment [40]. Concerning ANA, specific immunofluorescence pattern might help to diagnose patients. Anti-sp100, included in the "multiple nuclear dots" (MND) pattern, and anti-gp210, included in the "perinuclear rims pattern", are both specific for PBC; both correlate with disease severity, too [41].

Despite being rare, there are cases of variations of AMA in PBC, with AMA-positive subjects that may become AMA negative, and vice versa; this could be due to interference with the immune system and the onset of a new AID.

\section{Overlap Syndromes}

Autoimmune liver diseases, similarly to rheumatic disease, may overlap and present with both hepatocellular and cholangiocellular patterns according to biochemical, histologic, and imaging-based analysis. When left without treatment, these patients show a more progressive course toward liver cirrhosis and failure [19]. Despite PBC is featured with a certain degree of hepatic inflammation, it is usually minimal at histology. However, even after many years from diagnosis, PBC patients on treatment with UDCA (or second line obeticolic acid) may develop increased hepatitis activity; otherwise, features both of PBC and AIH may be observed from the diagnosis. In both cases, the condition is referred as "PBC-AIH overlap syndrome", defined by the Paris Criteria, and is observed in almost $8-10 \%$ of PBC patients (Table 2). The clues to an overlap syndrome consist of (i) serum alkaline phosphatase level more than twofold the upper limit of normal (ULN) at presentation, which is present in only $20 \%$ of patients with AIH; (ii) serum GGT level greater than ULN unimproved or worsened during therapy, (iii) AMA positivity, (iv) histologic findings of bile duct injury or loss, (v) concurrent IBD, and (vi) corticosteroid treatment failure or incomplete response [42].

On the other hand, patients know that AIH may develop signs of PBC; these subjects may test positive for AMA at diagnosis, but titers usually decrease over time. Also, in case of acute hepatitis activity, bile duct damage could be due to inflammation rather than AMA. Besides overlaps, transitions are also possible in rare cases from $\mathrm{PBC}$ to $\mathrm{AIH}$, or $\mathrm{AIH}$ to PBC [43].

\section{Non-Alcoholic Steatohepatitis}

Non-alcoholic fatty liver disease (NAFLD) is the most common liver disease nowadays, mainly associated with metabolic syndrome; it is characterized by steatosis, ballooning, and lobular inflammation, typically developing around the central veins [44]. When inflammation develops, NAFLD may evolve to non-alcoholic steatohepatitis (NASH) and eventually to cirrhosis and its complications; however, involvement of the biliary ducts is rare.

Previous studies have reported the detection of autoimmune markers (ANA, AMA, ASMA) in NAFLD, with prevalence ranging from 12 to $48 \%$, being higher than general population [45, 46] [47]. Clinical significance of these findings remains unclear so far, with controversial data concerning the disease course and outcomes.

Liver inflammation induced by NASH may potentially cause immunological cross-reactivity and induce AMA production, thus bile duct damage. As NASH patients may complicate with $\mathrm{PBC}$ or other autoimmune liver diseases, current guidelines recommend liver biopsy whenever in the presence of high titers of autoantibodies [48]. However, it is reasonable to consider autoantibody detection an epiphenomenon of NASH rather than a sign of underlying autoimmune liver disease in this subgroup of patients. In 2015, Ravi et al. identified 4 (1\%) AMA-positive patients upon a NAFLD cohort
Table 2 Diagnosis of overlap syndromes

\begin{tabular}{lll}
\hline & Laboratory features & Histologic findings \\
\hline AIH/PBC & ANA or SMA & Interface hepatitis \\
& Hypergammaglobulinemia & Lymphocytic portal infiltrate \\
& Serum IgG level increased & Portal plasma cells \\
& Marked serum AST/ALT abnormalities & Destructive cholangitis \\
& ALP or GGT $>$ ULN & \\
& AMA positive & Interface hepatitis (moderate to severe) \\
AIH/PBC (Paris & AIH features $(2$ of 3$)$ : & Destructive cholangitis \\
Criteria) & Serum ALT $>=$ fivefold ULN & \\
& Serum IgG $>=$ twofold ULN or SMA present & \\
& Interface hepatitis & \\
& PBC features $(2$ of 3$):$ & \\
& Serum ALP $>=$ twofold ULN or & \\
& GGT $>=$ fivefold ULN & \\
& AMA positive & \\
& Florid duct lesions &
\end{tabular}


of 398 patients with known autoimmune profile. Of note, 3 AMA patients had available liver histology, and two of them did not display any feature of PBC and had normal ALP levels; interestingly, AMA, ANA, or ASMA positivity was not associated with any difference in clinical presentation or natural history of NAFLD [49].

Furthermore, several data have been published concerning transient AMA positivity in patients with drug-induced liver injury (DILI). A recent study from Weber et al. shows that AMA positivity in a cohort of 143 patients with DILI is $10 \%$; this subgroup of patients had taken non-steroidal anti-inflammatory drugs more frequently and showed a more severe degree of liver injury, with higher aminotransferases, bilirubin and PT. However, data are scarce so far and future observations are required to look for any correlation with involved drug or clinical/biochemical characteristics [50].

\section{Viral Hepatitis}

AMA positivity in the absence of $\mathrm{PBC}$ has been observed in viral hepatitis, too. Chronic HCV hepatitis (CHC) has already been associated with the presence of autoantibodies such as ANA, rheumatoid factor, ASMA, AMA, antiliver-kidney microsomal antibody (LKM), and anti-soluble liver antigen (SLA); however, their clinical significance remains unclear. Literature reports controversial results concerning difference in demographic factors and clinical outcomes between CHC patient with and without autoantibodies [51-55]. Most of these studies showed sustained viral response (SVR) rates to be not significantly different between the two groups except for two studies in which rates were lower in $\mathrm{CHC}$ autoantibody positive; one of them showed interferon (IFN)-based regimen to be safe and effective in this setting, even if no patients included had AMA detection [51]. In 2018, Gilman et al. investigated a large cohort of HCV-infected patients tested positive for autoantibodies with the aim to identify potential association with cirrhosis and its complication such as hepatocellular carcinoma (HCC) [56]. Overall, 2.8\% of the population resulted AMA positive with no significant difference concerning sex nor ethnicity; also, the presence of an autoantibody had no impact on the prevalence of extrahepatic manifestation or natural history of CHC, except for SVR rates in IFN-based regimen $[51,56]$.

\section{Antimithocondrial Antibodies Beyond the Liver}

One in three PBC patients have a concomitant extrahepatic autoimmune disease, which may include rheumatological, endocrinological, gastrointestinal, pulmonary, or dermatological conditions. Among these, rheumatic diseases show an interesting overlap also in disease pathogenesis and treatment. Besides PBC, AMA positivity has been detected in other autoimmune disorders such as SSc, SLE, and SjS [27]. To note, $\mathrm{PBC}$ is associated with at least one concurrent extrahepatic autoimmune disorder in up to $61 \%$ of cases [57], with thyroid disease being one of the most common, especially in AMA-positive patients with an overall prevalence of $78 \%$ [58]. In a recent meta-analysis, extrahepatic autoimmune disorder is more frequent in AMA-positive PBC patients $(88 \%$ vs. $84 \%, p=0.05)$ and are associated with better biochemical analysis and early stage of disease at diagnosis [59].

\section{Systemic Sclerosis}

Up to $12 \%$ of $\mathrm{PBC}$ patients have coexisting SSc, and a large proportion of patients with SSc manifest a coexisting autoimmune condition, with $\mathrm{PBC}$ being the most frequent autoimmune liver disease, even though in clinical practice a higher percentage of SSc patients may have biochemical liver abnormalities without clinical significance [60-63]. $\mathrm{SSc}$ is an autoimmune disease of unknown origin characterized by microvascular damage and progressive fibrosis of skin that in severe cases can affect internal organs such as heart, lungs, and kidneys. The most frequently identified autoantibodies in SSc are anticentromere (ACA) - (30\%), anti-topo I (30\%), and -RNA pol III (4-20\%). However, several other autoantibodies can be identified in SSc patients and they can have an important role for their clinical and prognostic value [64].

It has been recently reported that AMA prevalence might be higher than expected in SSc patients, when sensitive techniques are used. In particular, using immunoprecipitation (IP) to test new and uncommon serum autoantibodies in SSc, it was observed that $15 \%$ of SSc sera manifests a novel IP pattern, comprising a set of 4 proteins corresponding to the $\mathrm{E} 1 \alpha, \mathrm{E} 1 \beta$, protein $\mathrm{X} / \mathrm{E} 3 \mathrm{BP}$, and $\mathrm{E} 2 / \mathrm{E} 3$ subunits of $\mathrm{PDC}$ recognized by AMA [29]. Even higher prevalence of PBCrelated autoantibodies in SSc patients have been reported by ELISA, with up to $25 \%$ of patients showing a positivity for anti-MIT3, gp210, and Sp100 antibodies (PBC-Screen), with higher risk of developing PBC or elevation of ALP; however, these tests need further validation [65].

Interestingly, when PBC and SSc coexist they are associated with the limited cutaneous form of SSc and positivity of ACA, and liver disease does not seem to worsen the prognosis of our AMA-positive patients with SSc [61].

\section{Systemic Lupus Erythematosus}

Systemic lupus erythematosus (SLE) is a chronic, autoimmune disease affecting women predominantly, especially between puberty and menopause [66]; it is characterized 
by a broad spectrum of clinical manifestations; however, its course and organ involvement are unpredictable. Similarly to other AID, the pathogenesis of SLE is multifactorial, with environmental factors acting in genetically predisposed individuals leading to the breaking of self-tolerance and impairment of the immune system; any organ or tissue may potentially be affected. In particular, B cell regulation may be involved and contribute with the production of autoantibodies which play an essential role in SLE, especially when they take part in immune complex formation [67].

SLE is characterized by the expression of autoantibodies to a wide variety of cellular antigens; ANA is for sure the most highly characteristic ones, followed by antibodies to native DNA (anti-dsDNA) and to Sm nuclear antigen (anti$\mathrm{Sm} / \mathrm{RNP}$ ), all included in the classification criteria. In fact, diagnosis of SLE is made on clinical manifestations and laboratory tests, functional tests and imaging according to either American College of Rheumatology Revised Criteria (ACR 2012) or Systemic Lupus International Collaborating Clinics classification criteria (SLICC 2012) [68-70]. Interestingly, autoantibody specificities overlap between the different clinical manifestations of SLE and positivity for a specific antibody does not necessarily mean that a certain organ will be affected; however, some autoantibodies are associated with peculiar clinical manifestations. Despite not having diagnostic clinical value in SLE patients, AMA are present in this subgroup of patients but with low prevalence. $\mathrm{Li}$ et al. found a significant percentage of AMA positivity in their Chinese cohort of SLE patients (approximately 15\%), but several other studies on European cohorts did not confirm such significant data maybe due to environmental or genetic background [71].

\section{Antiphospholipid Syndrome}

Antiphospholipid syndrome (APS) is a syndrome characterized by frequent and often multiple thromboses, both venous and arterial, and pregnancy morbidity; these clinical manifestations are usually associated with moderate thrombocytopenia [72].

Anti-cardiolipin antibodies (aCL) together with lupus anticoagulant (LA) are specific anti-phospholipid antibodies typical of APS may be primary, thus isolated findings, or secondary to other diseases, with SLE being one of the most common ones [73]. Interestingly, AMA-M1 target an antigen identical to cardiolipin, a phospholipid found uniquely in the inner mitochondrial membrane, and were originally identified in syphilis-infected patients [74]. Thus, the presence of AMA-M1/aCL clinically is associated with a greater risk of thrombotic events and thrombocytopenia. AMA-M5 have been identified in only $2 \%$ of patients by IIF, but specific antigenic target of these antibodies is undefined so far, even if lack of competition by cardiolipin-containing liposomes suggests, it is different from AMA-M1. They have been detected in patients with APS, SjS, and hemolytic anemia.

Recent evidence supports the fact that AMA are represented in the autoantibody repertoire associated with APS, may display different associations with the clinical manifestations of the disease. In particular, anti-DNA-IgM were associated with a lower likelihood of reporting a previous arterial thrombosis, and their levels were not influenced by the duration of the disease, cardiovascular risk factors or medications [75].

Weather AMA detection in SLE patients is associated with future development of $\mathrm{PBC}$ remains a question to be answered, with little risk identified so far $(<1 \%)$, with most of the patients having liver enzymes within the reference limit, or mild laboratory cholestasis [76, 77].

Interestingly, a recent pre-clinical study revealed a greater reactivity of antibodies in SLE sera to intact mitochondria rather than the M2 subunits to the 2-oxo-acid dehydrogenase protein complex, in clear distinction with sera of PBC patients. On the other hand, in the same analysis no significant binding of the PBC sera was found to intact mitochondria meaning PBC target antigens are not easily and immediately accessible [78]. Specifically, AMA-M2 are detected in approximately $10 \%$ of SLE patients, with not fully clear functional and clinical significance; so far, literature lacks solid, large cohort-based studies. However, emerging evidence suggests that SLE is characterized by activation of inflammation due to liberation of mitochondria; thus, further identification of mitochondrial antigens target by autoantibodies is needed to understand the role of mitochondrial in autoimmunity.

\section{Sjögren's Syndrome}

Sjögren's syndrome is a chronic, systemic autoimmune disease, which can be primary or secondary to other systemic AID, i.e., RA, SLE, SSc, mixed connective tissue disease, inflammatory muscle disease, autoimmune liver disease, and autoimmune thyroid disease $[79,80] . \mathrm{SjS}$ is the most common co-occurring condition in $\mathrm{PBC}$, in proportion ranging from 3.5 to nearly $100 \%$ of cases [57].

The pathogenesis of $\mathrm{SjS}$ is currently based on the concept of "autoimmune epithelitis", similarly to PBC, since in SjS the exocrine glands, especially salivary and lacrimal, are progressively destructed by an immune-mediated process $[20,81]$. PBC and SjS share a common immunopathogenesis in which genetics and environmental factors interact to result in disease onset inducing salivary or biliary epithelial cell apoptosis and contributing to the breakdown of tolerance to self-antigen exposed to the apoptotic blebs [20].

The diagnosis of $\mathrm{SjS}$ should be suspected in case of sicca syndrome symptoms, and an objective evaluation of eye dryness is obtained with a Schirmer's test which measures the 
normal tear production by the positioning of a strip of sterile filter paper overhanging the lateral third of the lower eyelid of each eye with $\mathrm{a} \leq 5 \mathrm{~mm}$ considered positive [82].

Systemic extraglandular manifestations are present in $10-15 \%$ of patients with $\mathrm{SjS}$, and arise from diverse pathogenetic mechanisms, being the result of the typical lymphocytic infiltration around the epithelium of target organs such as the liver, the kidney, and the bronchi/bronchioles, or the systemic form of the disease that arises from immunecomplex deposition, presenting with the clinical picture of vasculitis. Other extra-glandular manifestations include arthralgia and arthritis, and fatigue [81].

Anti-SSB are usually found with anti-SSA antibodies, while the only specificity in $25-40 \%$ of cases [83], and are not included in the latest classification criteria [84]. ANA, albeit not specific for $\mathrm{SjS}$, are present in up to $90 \%$ of cases, while RF is present in up to $70 \%$ of cases [83]. Histologic examination remains the gold standard for the diagnosis of SjS. Among SjS patients without overt autoimmune liver disease, up to $20 \%$ have detectable AMA, while $10 \%$ of $\mathrm{AIH}$-associated autoantibodies. Interestingly, previous studies reported that the association of $\mathrm{PBC}$ with $\mathrm{SjS}$ was associated with poorer prognosis and increased mortality [57, 85]. However, a recent study showed that the response and clinical outcomes of UDCA-treated patients with PBC are not adversely affected by concomitant $\mathrm{SjS}$ [86].

\section{Other Autoimmune Diseases}

There are several other, less recognized diseases that have higher prevalence among patients with $\mathrm{PBC}$. Among others, rheumatoid arthritis has been associated with $\mathrm{PBC}$, but epidemiological data only suggests a prevalence rate between $1.8 \%$ and 5.6\% [87, 88]. Data from national Danish and Swedish registers have shown an association between PBC and celiac disease, with up to $6 \%$ of patients having also celiac disease $[89,90]$. In contrast, other European studies from Poland and Italy have shown no prevalence greater than that seen in the general population [91, 92].

\section{Unexpected Associations}

\section{Inflammatory Myositis}

In the recent years, AMA have been associated with inflammatory myopathy, a heterogeneous disease entity affecting primarily the skeletal muscles. Myositis-specific antibodies as well as myositis-associated antibodies have been described to date, each associated with distinct clinic serological syndromes [93].

Myositis-specific antibodies are found only in patients with polymyositis, dermatomyositis, and immune-mediated necrotizing myopathies and have a strong association with clinical disease, meaning that patients with these specificities frequently have unique features characteristic of that antibody [93]. Conversely, myositis-associated antibodies are less well-defined, and are generally accepted to be those antibodies found in immune and inflammatory myopathies that can also be found in other AID, such as anti-PM-Scl, Ro52, and U1RNP. Having the antibody does not always correlate with the presence of inflammatory muscle disease, while other clinical associations can be seen [94]. These antibodies can be found alone, or in conjunction with other myositis-specific antibodies, and can also have typical clinical presentations. AMA are rarely present in inflammatory myopathy, but there is a growing recognition for this clinical entity [95].

Furthermore, AMA have been extensively associated with serious cardiac involvement $[96,97]$. In a large North American study on inflammatory myopathy, albeit AMA prevalence was extremely low $(0.006 \%)$, it was associated with a distinct phenotype with severe cardiac involvement, as severe conduction abnormalities and arrhythmias, cardiomyopathy, ventricular dilatations, and myocarditis, oftentimes occurring all in the same patient [97]. Other authors suggested that AMA-associated myopathy mimics sarcoidosis heart involvement, based on magnetic resonance findings, showing left ventricle systolic dysfunction [98]. Of interest, in the case of cardiomyopathy and myocarditis, treatment with immunosuppression could improve cardiac function. Fascinatingly, AMA have been reported in a significant proportion of patients with myocarditis as well as idiopathic dilated cardiomyopathy, where the most abundant protein in the inner mitochondrial membrane has been shown to be an organ specific autoantigen [99].

\section{SARS-CoV-2 Infection}

Since early 2020, SARS-CoV-2 infection has dramatically changed our perspectives. Of note, a case of PBC developing during or soon after COVID-19 has been reported [100]. Remarkably, the patient was diagnosed after being admitted for severe COVID-19 with the need of mechanical ventilation and treatment with tocilizumab, ceftriaxone, azithromycin, darunavir/cobicistat, anakinra, remdesivir, and fluconazole. During hospitalization, both GGT and ALP levels, that were normal at admission gradually increased, while serum bilirubin and ALT fluctuated between normal values and slightly elevated. An abdomen ultrasound showed a lightly enlarged liver with moderate steatosis and a mildly enlarged spleen, the liver stiffness measured with Fibroscan was $9.1 \mathrm{kPa}$. From the immunology standpoint, the patient tested positive for ANA and AMA (M2/BCOADC) at high titer. A liver biopsy was performed and showed florid ductal lesions, therefore leading to the definite diagnosis of PBC. 
This was the first reported case of PBC induced by SARSCoV-2, which is a RNA virus capable of inducing a profound activation of the immune system and also by the previous finding that infection by a human RNA beta-retrovirus, related to the mouse mammary tumor virus, was suggested as a possible trigger for PBC development [100].

\section{Conclusions}

The immune system scrupulously controls reactivity against self-antigens, and AID are relatively rare. Importantly, early diagnosis and treatment of AID can prevent morbidity and mortality and therefore specific diagnostic tools are critical. Currently, screening of AID (including PBC) relies heavily on the use of serological tests for the detection of serum autoantibodies, and a better understanding of such tests allows to ensure more efficient diagnosis. In these prospective, some issues regarding the clinical significance of AMAs remain to be addressed. First, determining the pathogenic role of AMA remains a priority for basic and clinical research in PBC. Indeed, although a pathogenic role in PBC has been extensively suggested, conclusive data are not available. Second, clinical implications of AMA presence in asymptomatic subjects remain an area for further discussion. Indeed, AMA represent the hallmark of $\mathrm{PBC}$, being present in more than $95 \%$ of patients even years before the development of clinical manifestations and diagnosis. Moreover, AMA are also associated with other AID, in particular $\mathrm{SjS}$, SSc, and SLE, while rarely detectable in healthy subjects. Finally, AMA positivity usually relies on the detection of autoantibodies directed towards the M2 subtype, and further research is needed to characterize the clinical significance of the other subtypes. With IIF being the gold standard for AMA detection, a newer technique validation is warranted to improve the test sensibility and therefore their clinical application.

\section{Declarations}

Conflict of Interest The authors declare no competing interests.

\section{References}

1. Arbuckle MR, McClain MT, Rubertone MV, Scofield RH, Dennis GJ, James JA et al (2003) Development of Autoantibodies before the Clinical Onset of Systemic Lupus Erythematosus. N Engl J Med 349(16):1526-33

2. Gulamhusein AF, Hirschfield GM (2018) Pathophysiology of primary biliary cholangitis. Best Pract Res Clin Gastroenterol 34-35:17-25

3. Bogdanos D-P, Pares A, Baum H, Caballeria L, Rigopoulou EI, Ma Y et al (2004) Disease-specific cross-reactivity between mimicking peptides of heat shock protein of mycobacterium gordonae and dominant epitope of E2 subunit of pyruvate dehydrogenase is common in Spanish but not British patients with primary biliary cirrhosis. J Autoimmun 22(4):353-62

4. Chantran Y, Ballot É, Johanet C (2013) Autoantibodies in primary biliary cirrhosis: Antimitochondrial autoantibodies. Clin Res Hepatol Gastroenterol 37(4):431-3

5. Calise SJ, Zheng B, Hasegawa T, Satoh M, Isailovic N, Ceribelli A et al (2018) Reference standards for the detection of antimitochondrial and anti-rods/rings autoantibodies. Clin Chem Lab Med 56(10):1789-98

6. Patel D, Egner W, Gleeson D, Wild G, Ward A (2002) Detection of serum M2 anti-mitochondrial antibodies by enzyme-linked immunosorbent assay is potentially less specific than by immunofluorescence. Ann Clin Biochem 39(3):304-7

7. Dähnrich C, Pares A, Caballeria L, Rosemann A, Schlumberger W, Probst C et al (2009) New ELISA for Detecting Primary Biliary Cirrhosis-Specific Antimitochondrial Antibodies. Clin Chem 55(5):978-85

8. Poyatos E, Morandeira F, Climent J, Mas V, Castellote J, Bas J (2021) Detection of anti-mitochondrial 2-oxoacid dehydrogenase complex subunit's antibodies for the diagnosis of primary biliary cholangitis. Clinical Immunol 108749

9. Berg PA, Klein R (1992) Antimitochondrial Antibodies in Primary Biliary Cirrhosis and Other Disorders: Definition and Clinical Relevance. Dig Dis 10(2):85-101

10. Muratori L, Granito A, Muratori P, Pappas G, Bianchi FB (2008) Antimitochondrial antibodies and other antibodies in primary biliary cirrhosis: diagnostic and prognostic value. Clin Liver Dis 12(2):261-276

11. Klein R, Berg PA (1988) Characterization of a new mitochondrial antigen-antibody system (M9/anti-M9) in patients with anti-M2 positive and anti-M2 negative primary biliary cirrhosis. Clin Exp Immunol 74(1):68-74

12. Beuers U, Gershwin ME, Gish RG, Invernizzi P, Jones DEJ, Lindor $\mathrm{K}$ et al (2015) Changing nomenclature for PBC: from 'cirrhosis' to 'cholangitis.' J Hepatol 63(5):1285-1287

13. Lleo A, Colapietro F (2018) Changes in the epidemiology of primary biliary cholangitis. Clin Liver Dis 22(3):429-441

14. Selmi C, Bowlus CL, Gershwin ME, Coppel RL (2011) Primary biliary cirrhosis. The Lancet 377(9777):1600-1609

15. Kaplan MM, Gershwin ME (2005) Primary biliary cirrhosis. N Engl J Med 353(12):1261-1273

16. Lleo A, Wang GQ, Gershwin ME, Hirschfield GM (2020) Primary biliary cholangitis. The Lancet 396(10266):1915-1926

17. Hirschfield GM, Beuers U, Corpechot C, Invernizzi P, Jones D, Marzioni M et al (2017) EASL Clinical Practice Guidelines: the diagnosis and management of patients with primary biliary cholangitis. J Hepatol 67(1):145-172

18. Neuberger J, Thomson R (1999) PBC and AMA? What is the connection? Hepatology 29(1):271-276

19. Selmi C, Generali E, Gershwin ME (2018) Rheumatic manifestations in autoimmune liver disease. Rheumatic Dis Clin North Am 44(1):65-87

20. Selmi C, Gershwin ME (2017) Chronic autoimmune epithelitis in Sjögren's syndrome and primary biliary cholangitis: a comprehensive review. Rheumatol Ther 4(2):263-279

21. Chen RCY, Naiyanetr P, Shu SA, Wang J, Yang GX, Kenny TP et al (2013) Antimitochondrial antibody heterogeneity and the xenobiotic etiology of primary biliary cirrhosis. Hepatology 57(4):1498-1508

22. Lleo A, Maroni L, Glaser S, Alpini G, Marzioni M (2014) Role of cholangiocytes in primary biliary cirrhosis. Semin Liver Dis 34(3):273-284 
23. Lleo A, Leung PSC, Hirschfield GM, Gershwin EM (2020) The pathogenesis of primary biliary cholangitis: a comprehensive review. Semin Liver Dis 40(01):034-048

24. Shuai Z, Wang J, Badamagunta M, Choi J, Yang G, Zhang W et al (2017) The fingerprint of antimitochondrial antibodies and the etiology of primary biliary cholangitis. Hepatology 65(5):1670-1682

25. Metcalf JV, Mitchison HC, Palmer JM, Jones DE, Bassendine MF, James OF (1996) Natural history of early primary biliary cirrhosis. The Lancet 348(9039):1399-1402

26. Zandanell S, Strasser M, Feldman A, Tevini J, Strebinger G, Niederseer D et al (2020) Low rate of new-onset primary biliary cholangitis in a cohort of anti-mitochondrial antibodypositive subjects over six years of follow-up. J Intern Med 287(4):395-404

27. Dahlquist G, Gaouar F, Carrat F, Meurisse S, Chazouillères O, Poupon R et al (2017) Large-scale characterization study of patients with antimitochondrial antibodies but nonestablished primary biliary cholangitis. Hepatology 65(1):152-163

28. Baldo DC, Dellavance A, Ferraz MLG, Andrade LEC (2019) Evolving liver inflammation in biochemically normal individuals with anti-mitochondria antibodies. Autoimmun Highlights 10(1): 10

29. Ceribelli A, Isailovic N, De Santis M, Generali E, Satoh M, Selmi C (2018) Detection of anti-mitochondrial antibodies by immunoprecipitation in patients with systemic sclerosis. J Immunol Methods 452:1-5

30. Yamagiwa S (2014) Autoantibodies in primary biliary cirrhosis: recent progress in research on the pathogenetic and clinical significance. WJG 20(10):2606

31. Joshi S, Cauch-Dudek K, Heathcote EJ, Lindor K, Jorgensen R, Klein R (2002) Antimitochondrial antibody profiles: are they valid prognostic indicators in primary biliary cirrhosis? Am J Gastroenterology 97(4):999-1002

32. Tang L, Zhong R, He X, Wang W, Liu J, Zhu Y et al (2017) Evidence for the association between IgG-antimitochondrial antibody and biochemical response to ursodeoxycholic acid treatment in primary biliary cholangitis: IgG-AMA and UDCA treatment. J Gastroenterol Hepatol 32(3):659-666

33. Zandanell S, Strasser M, Feldman A, Strebinger G, Aigner G, Niederseer D et al (2021) Similar clinical outcome of AMA immunoblot-M2-negative compared to immunoblot-positive subjects over six years of follow-up. Postgrad Med 133(3):291-298

34. Montano-Loza AJ, Hansen BE, Corpechot C, Roccarina D, Thorburn D, Trivedi P et al (2019) Factors associated with recurrence of primary biliary cholangitis after liver transplantation and effects on graft and patient survival. Gastroenterology 156(1):96-107.e1

35. Selmi C, Zuin M, Bowlus CL, Gershwin ME (2008) Antimitochondrial antibody-negative primary biliary cirrhosis. Clin Liver Dis 12(1):173-185

36. Bizzaro N, Covini G, Rosina F, Muratori P, Tonutti E, Villalta D et al (2012) Overcoming a "probable" diagnosis in antimitochondrial antibody negative primary biliary cirrhosis: study of 100 sera and review of the literature. Clinic Rev Allerg Immunol 42(3):288-297

37. Ozaslan E, Efe C, Ozaslan NG (2016) The diagnosis of antimitochondrial antibody-negative primary biliary cholangitis. Clin Res Hepatol Gastroenterol 40(5):553-561

38. de Liso F, Matinato C, Ronchi M, Maiavacca R (2017) The diagnostic accuracy of biomarkers for diagnosis of primary biliary cholangitis (PBC) in anti-mitochondrial antibody (AMA)negative PBC patients: A review of literature. Clin Chem Lab Med (CCLM) 56(1):25-31
39. Invernizzi P, Crosignani A, Battezzati PM, Covini G, De Valle G, Larghi A et al (1997) Comparison of the clinical features and clinical course of antimitochondrial antibody-positive and -negative primary biliary cirrhosis. Hepatology 25(5):1090-1095

40. Juliusson G, Imam M, Björnsson ES, Talwalkar JA, Lindor KD (2016) Long-term outcomes in antimitochondrial antibody negative primary biliary cirrhosis. Scand J Gastroenterol 51(6):745-752

41. Granito A, Yang WH, Muratori L, Lim MJ, Nakajima A, Ferri $S$ et al (2010) PML nuclear body component Sp140 is a novel autoantigen in primary biliary cirrhosis. Am J Gastroenterol 105(1):125-131

42. Czaja AJ, Carpenter HA (2017) Autoimmune hepatitis overlap syndromes and liver pathology. Gastroenterol Clin North Am 46(2):345-364

43. Czaja A (2001) Autoimmune hepatitis with incidental histologic features of bile duct injury. Hepatology 34(4):659-665

44. Neuschwander-Tetri BA, Caldwell SH (2003) Nonalcoholic steatohepatitis: summary of an AASLD Single Topic Conference. Hepatology 37(5):1202-1219

45. Adams LA, Lindor KD, Angulo P (2004) The prevalence of autoantibodies and autoimmune hepatitis in patients with nonalcoholic fatty liver disease. Am J Gastroenterol 99(7):1316-1320

46. Cotler SJ, Kanji K, Keshavarzian A, Jensen DM, Jakate S (2004) Prevalence and significance of autoantibodies in patients with non-alcoholic steatohepatitis. J Clin Gastroenterol 38(9):801-804

47. Loria P, Lonardo A, Leonardi F, Fontana C, Carulli L, Verrone AM et al (2003) Non-organ-specific autoantibodies in nonalcoholic fatty liver disease: prevalence and correlates. Dig Dis Sci 48(11):2173-2181

48. Vuppalanchi R, Gould RJ, Wilson LA, Unalp-Arida A, Cummings OW, Chalasani $\mathrm{N}$ et al (2012) Clinical significance of serum autoantibodies in patients with NAFLD: results from the nonalcoholic steatohepatitis clinical research network. Hepatol Int 6(1):379-385

49. Ravi S, Shoreibah M, Raff E, Bloomer J, Kakati D, Rasheed K et al (2015) Autoimmune markers do not impact clinical presentation or natural history of steatohepatitis-related liver disease. Dig Dis Sci 60(12):3788-3793

50. Weber S, Benesic A, Buchholtz ML, Rotter I, Gerbes AL (2021) Antimitochondrial rather than antinuclear antibodies correlate with severe drug-induced liver injury. Dig Dis 39(3):275-282

51. Clifford BD, Donahue D, Smith L, Cable E, Luttig B, Manns $M$ et al (1995) High prevalence of serological markers of autoimmunity in patients with chronic hepatitis C. Hepatology 21(3):613-619

52. Luo JC, Hwang SJ, Li CP, Lu RH, Chan CY, Wu JC et al (1998) Clinical significance of serum auto-antibodies in Chinese patients with chronic hepatitis C: negative role of serum viral titre and genotype. J Gastroenterol Hepatol 13(5):475-479

53. Cassani F, Cataleta M, Valentini P, Muratori P, Giostra F, Francesconi R et al (1997) Serum autoantibodies in chronic hepatitis C: comparison with autoimmune hepatitis and impact on the disease profile. Hepatology 26(3):561-566

54. Chen $\mathrm{CH}$, Lee CM, Chen $\mathrm{CH}$, Hu TH, Wang JH, Hung $\mathrm{CH}$ et al (2010) Prevalence and clinical relevance of serum autoantibodies in patients with chronic hepatitis C. Chang Gung Med J 33(3):258-265

55. Generali E, De Santis M, Isailovic N, Palermo B, Guidelli GM, Ceribelli A et al (2021) Rheumatoid factor and anti-citrullinated peptide antibodies in the general population: hepatitis B and C virus association and 15-year-risk of rheumatoid arthritis. Clin Exp Rheumatol 39(1):38-43

56. Gilman AJ, Le AK, Zhao C, Hoang J, Yasukawa LA, Weber SC et al (2018) Autoantibodies in chronic hepatitis $\mathrm{C}$ virus infection: impact on clinical outcomes and extrahepatic manifestations. BMJ Open Gastroenterol 5(1):e000203 
57. Floreani A, Franceschet I, Cazzagon N, Spinazzè A, Buja A, Furlan P et al (2015) Extrahepatic autoimmune conditions associated with primary biliary cirrhosis. Clin Rev Allergy Immunol 48(2-3):192-197

58. Floreani A, Mangini C, Reig A, Franceschet I, Cazzagon N, Perini L et al (2017) Thyroid dysfunction in primary biliary cholangitis: A comparative study at two European centers. Am J Gastroenterol 112(1):114-119

59. Efe C, Torgutalp M, Henriksson I, Alalkim F, Lytvyak E, Trivedi $\mathrm{H}$ et al (2021) Extrahepatic autoimmune diseases in primary biliary cholangitis: prevalence and significance for clinical presentation and disease outcome. J Gastroenterol Hepatol 36(4):936-942

60. Assassi S, Fritzler MJ, Arnett FC, Norman GL, Shah KR, Gourh $P$ et al (2009) Primary biliary cirrhosis (PBC), PBC autoantibodies, and hepatic parameter abnormalities in a large population of systemic sclerosis patients. J Rheumatol 36(10):2250-2256

61. Rigamonti C (2006) Clinical features and prognosis of primary biliary cirrhosis associated with systemic sclerosis. Gut 55(3):388-394

62. Liberal R, Grant CR, Sakkas L, Bizzaro N, Bogdanos DP (2013) Diagnostic and clinical significance of anti-centromere antibodies in primary biliary cirrhosis. Clin Res Hepatol Gastroenterol 37(6):572-585

63. Norman GL, Bialek A, Encabo S, Butkiewicz B, WiechowskaKozlowska A, Brzosko M et al (2009) Is prevalence of PBC underestimated in patients with systemic sclerosis? Dig Liver Dis 41(10): 762-764

64. Denton CP, Khanna D (2017) Systemic sclerosis. Lancet 390(10103):1685-1699

65. Cavazzana I, Ceribelli A, Taraborelli M, Fredi M, Norman G, Tincani A et al (2011) Primary biliary cirrhosis-related autoantibodies in a large cohort of Italian patients with systemic sclerosis. J Rheumatol 38(10):2180-2185

66. Rees F, Doherty M, Grainge M, Davenport G, Lanyon P, Zhang W (2016) The incidence and prevalence of systemic lupus erythematosus in the UK, 1999-2012. Ann Rheum Dis 75(1):136-141

67. Menon M, Blair PA, Isenberg DA, Mauri C (2016) A regulatory feedback between plasmacytoid dendritic cells and regulatory $\mathrm{B}$ cells is aberrant in systemic lupus erythematosus. Immunity 44(3):683-697

68. Hochberg MC (1997) Updating the American College of Rheumatology revised criteria for the classification of systemic lupus erythematosus. Arthritis Rheum 40(9): 1725

69. Tan EM, Cohen AS, Fries JF, Masi AT, McShane DJ, Rothfield NF et al (1982) The 1982 revised criteria for the classification of systemic lupus erythematosus. Arthritis Rheum 25(11):1271-1277

70. Petri M, Orbai AM, Alarcón GS, Gordon C, Merrill JT, Fortin PR et al (2012) Derivation and validation of the systemic lupus international collaborating clinics classification criteria for systemic lupus erythematosus. Arthritis Rheum 64(8):2677-2686

71. Li CH, Xu PS, Wang CY, Zou GL (2006) Increased serum aminotransferases associated with anti-mitochondrial antibodies in systemic lupus erythematosus patients with autoimmune liver disease. Clin Chim Acta 365(1-2):135-142

72. Garcia D, Erkan D (2018) Diagnosis and management of the antiphospholipid syndrome. N Engl J Med 378(21):2010-2021

73. Selmi C, De Santis M, Battezzati PM, Generali E, Lari SA, Ceribelli A et al (2020) Anti-phospholipid antibody prevalence and association with subclinical atherosclerosis and atherothrombosis in the general population. Int J Cardiol 300:209-213

74. Harris EN, Gharavi AE, Boey ML, Patel BM, Mackworth-Young CG, Loizou S et al (1983) Anticardiolipin antibodies: detection by radioimmunoassay and association with thrombosis in systemic lupus erythematosus. Lancet 2(8361):1211-1214
75. Becker YL, Julien AS, Godbout A, Boilard É, Fortin PR (2020) Pilot study of anti-mitochondrial antibodies in antiphospholipid syndrome. Lupus 29(12):1623-1629

76. Ahmad A, Heijke R, Eriksson P, Wirestam L, Kechagias S, Dahle $C$ et al (2021) Autoantibodies associated with primary biliary cholangitis are common among patients with systemic lupus erythematosus even in the absence of elevated liver enzymes. Clin Exp Immunol 203(1):22-31

77. Becker Y, Loignon RC, Julien AS, Marcoux G, Allaeys I, Lévesque $\mathrm{T}$ et al (2019) Anti-mitochondrial autoantibodies in systemic lupus erythematosus and their association with disease manifestations. Sci Rep 9(1):4530

78. Lai JH, Hung LF, Huang CY, Wu DW, Wu CH, Ho LJ (2021) Mitochondrial protein CMPK2 regulates IFN alpha-enhanced foam cell formation, potentially contributing to premature atherosclerosis in SLE. Arthritis Res Ther 23(1):120

79. Vivino FB (2017) Sjogren's syndrome: clinical aspects. Clin Immunol 182:48-54

80. Theander E, Jacobsson LTH (2008) Relationship of Sjögren's syndrome to other connective tissue and autoimmune disorders. Rheum Dis Clin North Am 34(4):935-47, viii-ix

81. Generali E, Costanzo A, Mainetti C, Selmi C (2017) Cutaneous and mucosal manifestations of Sjögren's syndrome. Clin Rev Allergy Immunol 53(3):357-370

82. Yao Y, Ma JF, Chang C, Xu T, Gao CY, Gershwin ME et al (2021) Immunobiology of T cells in Sjögren's syndrome. Clin Rev Allergy Immunol 60(1):111-131

83. Shen L, Suresh L (2017) Autoantibodies, detection methods and panels for diagnosis of Sjögren's syndrome. Clin Immunol 182:24-29

84. Shiboski CH, Shiboski SC, Seror R, Criswell LA, Labetoulle M, Lietman TM et al (2017) 2016 American College of Rheumatology/European League Against Rheumatism classification criteria for primary Sjögren's syndrome: A consensus and data-driven methodology involving three international patient cohorts. Ann Rheum Dis 76(1):9-16

85. Chen CT, Tseng YC, Yang CW, Lin HH, Chen PJ, Huang TY et al (2016) Increased risks of spontaneous bacterial peritonitis and interstitial lung disease in primary biliary cirrhosis patients with concomitant Sjögren syndrome. Medicine 95(2):e2537

86. Ni P, Men R, Shen M, Wang T, Huang C, Fan X et al (2019) Concomitant Sjögren's syndrome was not associated with a poorer response or outcomes in ursodeoxycholic acid-treated patients with primary biliary cholangitis. Can J Gastroenterol Hepatol 2019:7396870

87. Marasini B (2001) Rheumatic disorders and primary biliary cirrhosis: an appraisal of 170 Italian patients. Ann Rheum Dis 60(11):1046-1049

88. Caramella C, Avouac J, Sogni P, Puéchal X, Kahan A, Allanore $Y$ (2007) Association between rheumatoid arthritis and primary biliary cirrhosis. Joint Bone Spine 74(3):279-281

89. Sorensen HT, Thulstrup AM, Blomqvist P, Nørgaard B, Fonager K, Ekbom A (1999) Risk of primary biliary liver cirrhosis in patients with coeliac disease: Danish and Swedish cohort data. Gut 44(5):736-738

90. Kingham JG, Parker DR (1998) The association between primary biliary cirrhosis and coeliac disease: a study of relative prevalences. Gut 42(1):120-122

91. Habior A, Lewartowska A, Orłowska J, Zych W, Sankowska M, Bauer A et al (2003) Association of coeliac disease with primary biliary cirrhosis in Poland. Eur J Gastroenterol Hepatol 15(2):159-164

92. Bardella MT, Quatrini M, Zuin M, Podda M, Cesarini L, Velio P et al (1997) Screening patients with celiac disease for 
primary biliary cirrhosis and vice versa. Am J Gastroenterol 92(9):1524-1526

93. Satoh M, Tanaka S, Ceribelli A, Calise SJ, Chan EKL (2017) A comprehensive overview on myositis-specific antibodies: New and old biomarkers in idiopathic inflammatory myopathy. Clin Rev Allergy Immunol 52(1):1-19

94. Ceribelli A, Isailovic N, De Santis M, Generali E, Fredi M, Cavazzana I et al (2017) Myositis-specific autoantibodies and their association with malignancy in Italian patients with polymyositis and dermatomyositis. Clin Rheumatol 36(2):469-475

95. Minamiyama S, Ueda S, Nakashima R, Yamakado H, Sakato Y, Yamashita $\mathrm{H}$ et al (2020) Thigh muscle MRI findings in myopathy associated with anti-mitochondrial antibody. Muscle Nerve 61(1):81-87

96. Maeda MH, Tsuji S, Shimizu J (2012) Inflammatory myopathies associated with anti-mitochondrial antibodies. Brain 135(6): 1767-1777

97. Albayda J, Khan A, Casciola-Rosen L, Corse AM, Paik JJ, Christopher-Stine L (2018) Inflammatory myopathy associated with anti-mitochondrial antibodies: a distinct phenotype with cardiac involvement. Semin Arthritis Rheum 47(4):552-556

98. Kadosaka T, Tsujinaga S, Iwano H, Kamiya K, Nagai A, Mizuguchi Y et al (2020) Cardiac involvement with anti-mitochondrial antibodypositive myositis mimicking cardiac sarcoidosis. ESC Heart Failure 7(6):4315-4319

99. Schultheiss H, Bolte H (1985) Immunological analysis of autoantibodies against the adenine nucleotide translocator in dilated cardiomyopathy. J Mol Cell Cardiol 17(6):603-617

100. Bartoli A, Gitto S, Sighinolfi P, Cursaro C, Andreone P (2021) Primary biliary cholangitis associated with SARS-CoV-2 infection. J Hepatol 74(5):1245-1246

101. Hatzis GS, Fragoulis GE, Karatzaferis A, Delladetsima I, Barbatis C, Moutsopoulos HM (2008) Prevalence and longterm course of primary biliary cirrhosis in primary Sjögren's syndrome. J Rheumatol 35(10):2012-2016

102. Imura-Kumada S, Hasegawa M, Matsushita T, Hamaguchi Y, Encabo S, Shums Z et al (2012) High prevalence of primary biliary cirrhosis and disease-associated autoantibodies in Japanese patients with systemic sclerosis. Mod Rheumatol 22(6):892-898

103. Ranua J, Luoma K, Auvinen A, Haapala A-M, Mäki M, Peltola $\mathrm{J}$ et al (2005) Antimitochondrial antibodies in patients with epilepsy. Epilepsy Behav 7(1):95-97

104. Laadhar L, Zitouni M, Kallel-Sellami M, Bouguerra R, Chaabouni H, Makni S (2007) Spectrum of autoantibodies in Tunisian adult type 1 diabetes mellitus. Ann N Y Acad Sci 1107:356-362

105. Lazaridis KN, Juran BD, Boe GM, Slusser JP, de Andrade M, Homburger HA et al (2007) Increased prevalence of antimitochondrial antibodies in first-degree relatives of patients with primary biliary cirrhosis. Hepatology 46(3):785-792
106. Li BA, Liu J, Hou J, Tang J, Zhang J, Xu J et al (2015) Autoantibodies in Chinese patients with chronic hepatitis B: prevalence and clinical associations. World J Gastroenterol 21(1):283-291

107. Liu CW, Huang YC (2018) Vitiligo and autoantibodies: a systematic review and meta-analysis. J Dtsch Dermatol Ges 16(7):845-851

108. Marconcini ML, Fayad L, Shiozawa MBC, Dantas-Correa EB, de Lucca Schiavon L, Narciso-Schiavon JL (2013) Autoantibody profile in individuals with chronic hepatitis C. Rev Soc Bras Med Trop 46(2):147-153

109. Mattalia A, Quaranta S, Leung PS, Bauducci M, Van de Water J, Calvo PL et al (1998) Characterization of antimitochondrial antibodies in health adults. Hepatology 27(3):656-61

110. Pelka K, Stec-Polak M, Wojas-Pelc A, Pastuszczak M (2021) Prevalence of antimitochondrial antibodies in subacute cutaneous lupus erythematosus. Int J Dermatol 60(1):88-92

111. Pope JE, Thompson A (1999) Antimitochondrial antibodies and their significance in diffuse and limited scleroderma. J Clin Rheumatol 5(4):206-209

112. Ramos-Casals M, Pares A, Jara LJ, Solans R, Viñas O, Vázquez P et al (2005) Antimitochondrial antibodies in patients with chronic hepatitis $C$ virus infection: description of 18 cases and review of the literature. J Viral Hepat 12(6):648-654

113. Shibata M, Onozuka Y, Morizane T, Koizumi H, Kawaguchi N, Miyakawa $\mathrm{H}$ et al (2004) Prevalence of antimitochondrial antibody in Japanese corporate workers in Kanagawa prefecture. J Gastroenterol 39(3):255-259

114. Beretta-Piccoli BT, Ripellino P, Gobbi C, Cerny A, Baserga A, Di Bartolomeo C et al (2018) Autoimmune liver disease serology in acute hepatitis E virus infection. J Autoimmun 94:1-6

115. Turchany JM, Uibo R, Kivik T, Van de Water J, Prindiville T, Coppel RL et al (1997) A study of antimitochondrial antibodies in a random population in Estonia. Am J Gastroenterol 92(1):124-6

116. Wielosz E, Majdan M, Koszarny A, Dryglewska M, Tabarkiewicz J (2016) Presence of organ-specific antibodies in patients with systemic sclerosis. Pol Arch Med Wewn 126(11):862-869

117. Yokokawa T, Yoshihisa A, Misaka T, Sato T, Kaneshiro T, Oikawa $\mathrm{M}$ et al (2021) Anti-mitochondrial antibodies in patients with dilated cardiomyopathy. Intern Med 60(2):201-208

118. Zografos TA, Gatselis N, Zachou K, Liaskos C, Gabeta S, Koukoulis GK et al (2012) Primary biliary cirrhosis-specific autoantibodies in first degree relatives of Greek primary biliary cirrhosis patients. World J Gastroenterol 18(34):4721-4728

Publisher's Note Springer Nature remains neutral with regard to jurisdictional claims in published maps and institutional affiliations. 